
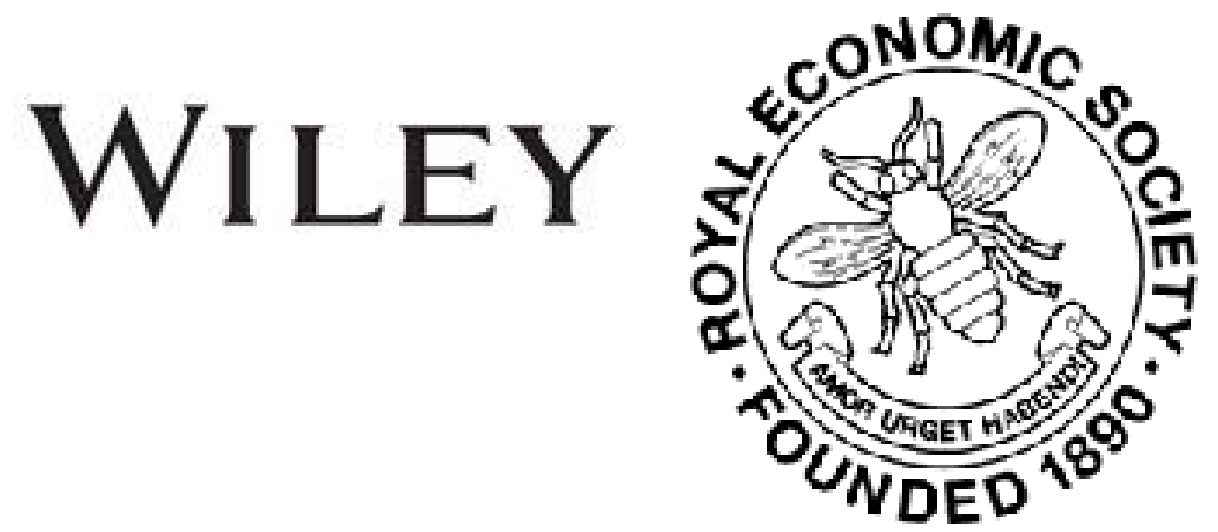

A Note on the Incidence of Protective Import Duties Author(s): S. J. Chapman

Source: The Economic Journal, Vol. 19, No. 73 (Mar., 1909), pp. 133-139

Published by: Wiley on behalf of the Royal Economic Society

Stable URL: http://www.jstor.org/stable/2220531

Accessed: 20-06-2016 07:30 UTC

Your use of the JSTOR archive indicates your acceptance of the Terms \& Conditions of Use, available at

http://about.jstor.org/terms

JSTOR is a not-for-profit service that helps scholars, researchers, and students discover, use, and build upon a wide range of content in a trusted digital archive. We use information technology and tools to increase productivity and facilitate new forms of scholarship. For more information about JSTOR, please contact support@jstor.org.

Wiley, Royal Economic Society are collaborating with JSTOR to digitize, preserve and extend access to The Economic Journal 
The following table shows the figures for the previous two months, March and April, 1908 :-

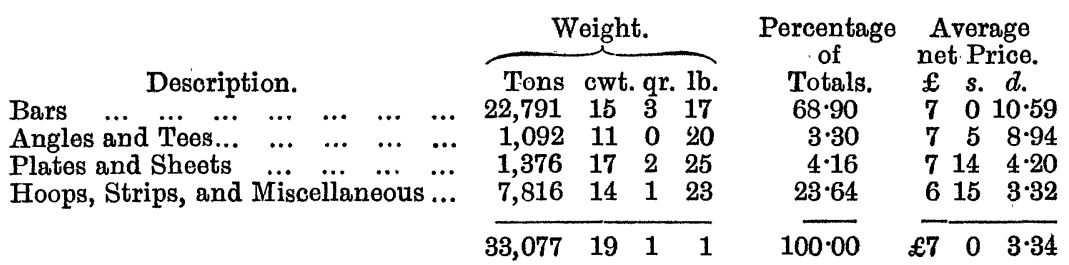

A. Dudley Evans

\section{A Note on the Incidence of Protective Import Duties. ${ }^{1}$}

IT is not unusual for a country which imposes import duties to produce itself the articles which it taxes (for instance, when its aim is protection), and it is not unusual for the countries trading with it to produce also for themselves, or procure from yet other countries, articles of the same kind as those which they import from the taxing country. These are the circumstances which I propose to investigate in the present article.

Let there be (i.) two countries ( $P$, the taxing country, and $Q$ ), (ii.) two commodities ( $A$, the taxed commodity, and $B$ ), and suppose (iii.) that both $P$ and $Q$ produced both $A$ and $B$ before the imposition of the import duty and continued to produce both commodities afterwards. In making the third assumption in our abstract treatment we are merely limiting the broad application of our results. to cases in which a country levying an import duty has not succeeded in completely ousting competitors as regards her exports, and goods which have paid the import duty meet in the markets of the taxing country with untaxed rival goods with which they had also been in competition before the import duty was levied. If gains and losses in the taxing country be reckoned in terms of some non-exportable commodity, or service, the quantity of which is not affected appreciably by changes in foreign trade (say domestic service), the effect of an import duty upon the taxing country becomes measurable.

Cost of transport being ignored, the ratio between the costs of production of $A$ and $B$ must have been identical in $P$ and $Q$

1 Mr. Bickerdike's speculations on the incidence of incipient import duties [EConomic Journal, Vol. VI, p. 529] are the prime occasion of this note, but I deal only with trade of a particular, though not of an exceptional, kind. 
before the imposition of the tax; and after the imposition of the $\operatorname{tax}$ on the imports of $A, \frac{\text { cost of production of } A \text { in } P \text { less the tax }}{\text { cost of production of } B \text { in } P}$ must equal $\frac{\text { cost of production of } A \text { in } Q}{\text { cost of production of } B \text { in } Q}$. These premisses, com. bined with ordinarily accepted propositions relating to the determination of value, yield the results set forth below. In the first and more complicated argument (i.) producers' rent is taken into account as well as consumers' rent when production is subject to decreasing returns, and (ii.) in the case of constant and increasing returns, variations in total price (in units of constant value) are supposed to measure variations in total real costs. ${ }^{1}$ In the second argument (at the end of this article) producers' rents are disregarded altogether. There is much to be said for ignoring all producers' rents in most problems of international trade.

The conclusions are as follows. ${ }^{2}$ The gain or loss resulting

1 As regards both these points I have followed good precedents, but it may be ncidentally observed that in many cases producers' rent is of small importance

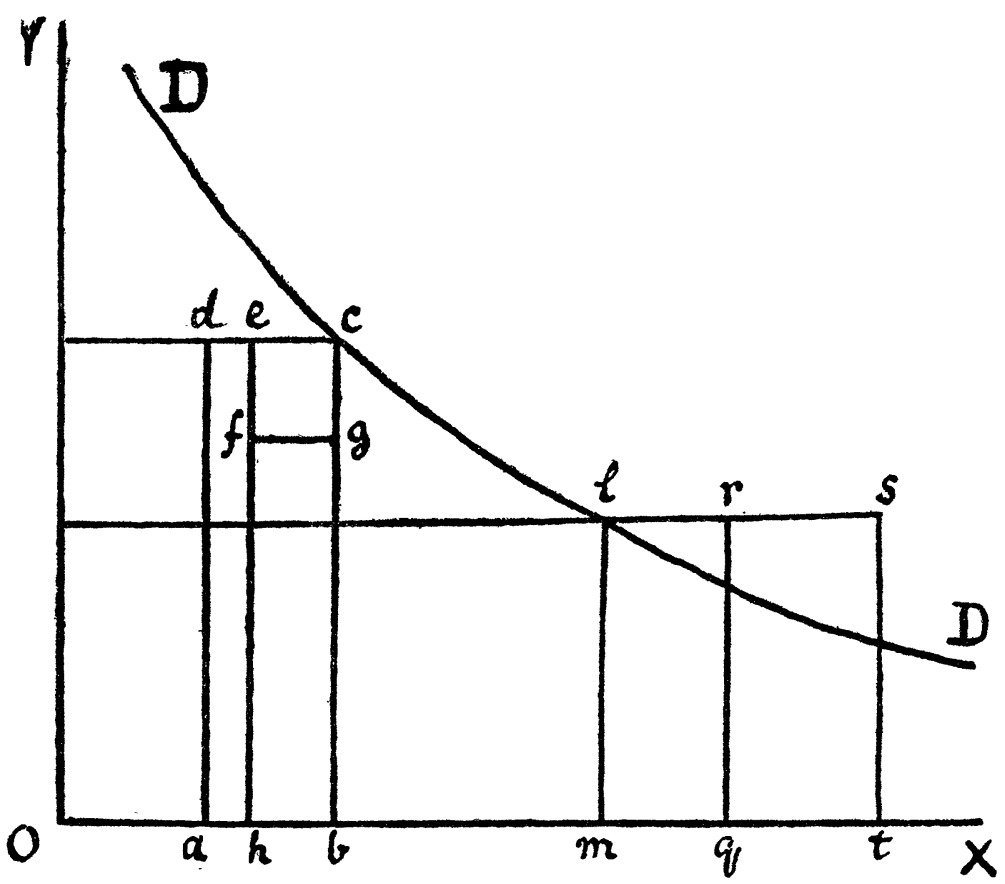

compared with consumers' rent, and that producers' rent is not strictly a thing to be ignored when constant or increasing returns is in operation.

2 The proofs are too lengthy for insertion, but their nature may be indicated. With reference to country $P$ let $c, h$ indicate consumption and home production of $A$ respectively before the imposition of the import duty, the rate of which per unit 
from the tax may be represented in every case as twice the proceeds of the tax (written hereafter as $2 T$ ) plus or minus certain quantities according as $A$ or $B$ is subject to increasing or decreasing returns in the taxing country. These quantities are described beneath. To each a sign is appended which is used afterwards for the sake of brevity. The letters $p, c, i, e$ mean respectively price, consumption, imports, and exports before the imposition of the tax, and $p_{1}, c_{1}, i_{1}, e_{1}$ the same when reference is made to conditions after the imposition of the tax. The $A$ or $B$ terminating each sign indicates the commodity to which it relates.

If $A$ is subject to increasing returns in $P$, there is added to the account as gain an amount equal to the fall in price of $A$ in $P$, consequent upon the tax, multiplied by the average of the quanti-

is indicated by $t$, and $c_{1}, h_{1}$ the same afterwards. Let $c^{1}, h^{1}, c_{1}{ }^{1}, h_{1}{ }^{1}$ indicate corresponding facts with reference to $B$. Similarly, let $i, e, i_{1}, e_{1}$ stand for imports and exports before and after the tax. Satisfactions of consumption are functions $(F, f)$ of the quantities of $A$ and $B$ consumed, and total costs are functions $(\phi, \Phi)$ of quantities produced, both being reckoned in units of constant value. Then,

Gain or loss $=u=t i_{1}+\left\{F\left(c_{1}\right)+f\left(c_{1}{ }^{1}\right)-\Phi\left(h_{1}\right)-\phi\left(h_{1}{ }^{1}\right)\right\}-\left\{F^{\prime}(c)+F^{\prime}\left(c^{1}\right)-\Phi(h)-\phi\left(h^{1}\right)\right\}$.

It will be sufficient to suggest the line of argument by giving the detailed working - which occupies little space-in the simple case, when $A$ and $B$ are subject to constant returns in $P$.

I shall state the argument in geometrical form so that all can follow it.

In the figure above let $D$ represent demand for both $A$ and $B$ in the taxing country $P$. Along $O X$ measure quantities of $A$ and $B$, and along $O Y$ units of some non-exportable good, such as domestic service. Suppose that before the imposition of the import duty $P$ produces $O a$ and imports $a b$ of $A$ and produces $O t$ and exports $m t$ of $B$. Evidently, at the position of equilibrium, $l t=d b$. Let a tax, $c g$, be imposed on importations of $A$, and let importations of $A$ contract in consequence to $h b$. Exportations of $B$ will then contract to $m q, m q$ being such that $l q=f b$. There is plainly a gain to $P$. This gain, since consumers' rent is unaffected, consists in the proceeds of the import duty $(e g)$ plus the saving on production of $B$ for export $(r t)$, less the increased expenditure on the production of $A$ for home consumption $(d h)$. That is to say, calling the gain $U$,

$$
U=e g+r t-d h \text {. }
$$

And, ex hypothesi, $d b=l t$, and $f b=l q$,

$$
\begin{gathered}
\therefore r t=d h+e g . \\
\therefore \quad U=e g+d h+e g-d h . \\
=2 e g .
\end{gathered}
$$

That is to say, the gain equals twice the proceeds of the import duty.

In other cases the argument is more involved, but no new principles are introduced.

As arising out of these investigations, it is interesting to note that prices need not be raised in the long period in the country which imposes import duties. In the cases supposed in this article there is only a balance in the long run of bullion imported by the taxing country, in consequence of the tax, when the real cost of the untaxed commodity in the country importing it rises relatively to the real cost of that commodity in the country exporting it. At first, of course, bullion must flow to the taxing country, but ultimately some may flow in the opposite direction, and perhaps a larger quantity. 
ties of $A$ consumed in $P$ before and after the imposition of the $\operatorname{tax}\left(\right.$ i.e. $\left.\left(p-p_{1}\right) \frac{c+c_{1}}{2} A\right)$.

If $A$ is subject to decreasing returns, there is added to the account as loss an amount equal to the rise in the price of $A$ in $P$, consequent upon the tax, multiplied by the average of the quantities of $A$ imported by $P$ before and after the tax

$$
\text { (i.e. } \left.\left(p_{1}-p\right) \frac{i+i_{1}}{2} A\right) \text {. }
$$

If $B$ is subject to increasing returns, there is added to the account as loss an amount equal to the rise in the price of $B$ in $P$, indirectly consequent upon the tax, multiplied by the average of the quantities of $B$ consumed in $P$ before and after the tax

$$
\text { (i.e. } \left.\left(p_{1}-p\right) \frac{c+c_{1}}{2} B\right) \text {. }
$$

If $B$ is subject to decreasing returns, there is added to the account as loss an amount equal to the fall in the price of $' B$ in $P$, indirectly consequent upon the tax, multiplied by the average of the quantities of $B$ exported by $P$ before and after the tax

$$
\text { (i.e. } \left.\left(p-p_{1}\right) \frac{e+e_{1}}{2} B\right) \text {. }
$$

The extent to which imports contract depends as much, of course, upon the conditions of demand and supply in $Q$ as upon those in $P$. A very small tax might cause a considerable contraction, since in $Q$ a large transference of labour and capital from the production $A$ to that of $B$ might be required to bring to equivalence $\frac{\text { cost of production of } A \text { in } P \text { less the tax }}{\text { cost of production of } B \text { in } P}$ $\frac{\text { cost of production of } A \text { in } Q}{\text { cost of production of } B \text { in } Q}$.

Now in $P$ either $A$ or $B$ can be subject to constant, increasing, or decreasing returns, independently of the conditions of production which apply to the other. This becomes evident when we bear in mind that the sole condition of equilibrium being restored after the imposition of the tax, without the production of $A$ or $B$ ceasing in either country, is that the ratios

and

$$
\frac{\text { cost of production of } A \text { in } P \text { less the tax }}{\text { cost of production of } B \text { in } P}
$$

$$
\frac{\text { cost of production of } A \text { in } Q}{\text { cost of production of } B \text { in } Q} \text {, }
$$

1 Hence it will be seen that fractions cannot theoretically be eliminated from the expressions $\frac{c+c_{1}}{2} A, \frac{e+e_{1}}{2} B, \& c$. , even if the import duty is very small. 
which, on the first imposition of the duty, must be different, should converge sufficiently, as a result of the trade induced, to come to equivalence before either industry had contracted to zero in either country; and, of course, the relation between the output and cost of a commodity need not be of the same character in both countries. Hence there are nine cases to which to assign gain or loss. ${ }^{1}$

If the production of $B$ in $P$ is subject to constant returns, $P$ must gain $2 T$ or more from the tax, except in the case of $A$ being produced in $P$ under conditions of decreasing returns, when

$$
\text { gain or loss }=u=2 T-\left(p_{1}-p\right) \frac{i+i_{1}}{2} A \text {. }
$$

Let $t$ be the amount of the tax per unit. Now $p_{1}-p$ may be equal to, less than, or greater than $t$-even considerably greater than $t$, though this is not likely. Hence $2 T$ may be less than

$$
\left(p_{1}-p\right) \frac{i+i_{1}}{2} A \text {. }
$$

If the production of $B$ in $P$ is subject to increasing returns, the sign of $u$ is theoretically doubtful. The $a$ priori probability would seem to be gain if the production of $A$ also is subject to increasing returns in $\mathrm{P}$, since in the absence of knoweldge to the contrary there is no reason for supposing that either $\left(p-p_{1}\right) \frac{c+c_{1}}{2} A$ or $\left(p_{1}-p\right) \frac{c+c_{1}}{2} B$ will appreciably exceed the other. ${ }^{2}$ If, with the production of $B$ subject to increasing returns in $P, A$ is produced under conditions of constant returns in $P$, the probability of a loss would be high were the importation of $A$ after the imposition of the duty small in relation to the home consumption of $B$, or were $\left(p_{1}-p\right) B$ large, which is not unlikely-and the loss might be considerable. The probability of loss is still higher when the output of $A$ is subject to decreasing returns.

If the production of $B$ in $P$ is subject to decreasing returns,

I I cannot accept the view that diminishing returns in the long period is to be regarded as normal in articles traded in internationally, and a priori probability is a dangerous weapon to invoke in a case of this kind. What is a priori probable may be actually most improbable. I doubt the expediency of arguing as if half the value consumed in the world were produced at diminishing returns and half at increasing returns ; and, as regards the class of trade that I have been considering, oven the assumption that all production is subject to decreasing returns would not establish that gain is always or almost always made from imposing a small import duty.

2 This conclusion raises the question whether equal absolute quantities of contraction of a large and a small industry have about the same effect on price as a rule, for usually exports will contract more than imports, and exporting industries may be expected therefore to be larger, as a rule, than industries competing with imports. 
all three cases are theoretically doubtful. The probability would seem to be gain if the output of $A$ in $P$ were subject to increasing returns, but loss would be almost certain if it were subject to decreasing returns.

The nature of these results is not altered by the tax being made very small. The doubtful cases might be divided up into a number of determinable cases by an analysis of the elasticities of supply and demand in $Q$ also, but the solution of the problem would then be made highly complicated, and the results reached here are sufficient to establish the point that gain from a small tax is far from being general under the conditions supposed in this paper. As regards the practical application of these results, we may remark that in many instances it is not difficult to pick out from the foreign trade of any country a limited number of leading lines which in comparison dwarf the rest of the trade.

As final generalisations, when the producers' rent associated with decreasing returns is allowed for, the following propositions may be laid down :-

The most favourable conditions for gain exist when increasing returns rule in the protected home industries, and constant returns, inclining rather to decreasing returns than increasing returns, rule in the exporting industries. The gain might be expected to exceed $2 T$, and perhaps by a large amount.

The conditions most likely to result in loss are found when diminishing returns rule in the home industries competing with imports, and increasing returns apply to the industries exporting. The loss might be considerable.

In the above argument, as already stated, the producers' rent earned on the production of an article subject to decreasing returns has been taken into account. I shall now point out what the results would be if all producers' rents were disregarded. The only alterations to be made are these :-

If $A$ is subject to decreasing returns the gain of $2 T$ is reduced by $\left(p_{1}-p\right) \frac{c+c_{1}}{2} A$ instead of $\left(p_{1}-p\right) \frac{i+i_{1}}{2} A$. If $B$ is subject to decreasing returns the gain of $2 T$ is augmented by $\left(p-p_{1}\right) \frac{c+c_{1}}{2} B$ instead of being reduced by $\left(p-p_{1}\right) \frac{e+e_{1}}{2} B$. Thus the quantities to be added as gain or loss to $2 T$ are always the differences between the aggregates of prices (measured in units of constant value) paid in $P$ for $A$ and $B$ before and after the imposition of the duty-that is to say, the effect is the gain or loss of consumers' 
rent plus $2 T$. The practical conclüsions now become as follows. When $B$ is, and $A$ is not, subject to decreasing returns in $P$, gain is certain-it is greatest, of course, when $A$ is subject to increasing returns. When $B$ is subject to increasing returns and $A$ to decreasing returns in $P$, loss is practically certain, since $2 T$ is not likely to exceed $\left(p_{1}-p\right) \frac{c+c_{1}}{2} A+\left(p-p_{1}\right) \frac{c+c_{1}}{2} B$. The effects in all other cases are doubtful-the evaluation of the probability of gain or loss in each can be left to the reader.

S. J. Chapman

\section{The Economic Legislation of the Year 1908.}

Notwithstanding the unusual amount of time devoted to measures which failed to reach the Statute Book, the number of public general Acts, seventy-one, passed by Parliament during the last year was beyond the average. The year is likely to be well remembered by the passing of the following Acts of supreme importance, viz., the Old Age Pensions Act, the Coal Mines (Eight Hours Act), the Port of London Act, and the Children Act. The latter, however, is outside the scope of the present summary, which deals only with the legislation of a more purely economic character. It is sometimes difficult to draw a definite line, as many measures are of such a wide-reaching character.

The same difficulty is found in attempting to classify the Acts under heads, as they affect different interests. The following is the classification here adopted :-(I.) Financial; (II.) Commercial; (III.) Industrial; (IV.) Agricultural and Fisheries; (V.) Social Reform; (VI.) Public Services.

\section{Financial.}

With regard to matters of finance, it is satisfactory to notice that the revenue for the year 1907-8 was $£ 156,538,000$ and the expenditure $£ 151,812,000$, giving a realised surplus of $£ 4,726,000$, which, subject to certain deductions, was applied to the reduction of the National Debt. The revenue for the year ending March 31st, 1909, is estimated at $£ 157,770,000$ and the expenditure at $£ 152,869,000$, promising a surplus of $£ 4,901,000$. It is of special interest to note that $£ 1,200,000$ of this amount is to be set aside for the first three months' payments for Old Age Pensions.

By the Appropriation Act (c. 30 ) nearly 34 millions was to 